\title{
Correction
}

\section{Correction: Basso et al., Transglutaminase Inhibition Protects against Oxidative Stress-Induced Neuronal Death Downstream of Pathological ERK Activation}

In the article "Transglutaminase Inhibition Protects against Oxidative Stress-Induced Neuronal Death Downstream of Pathological ERK Activation” by Manuela Basso, Jill Berlin, Li Xia, Sama F. Sleiman, Brendan Ko, Renee Haskew-Layton, Eunhee Kim, Marc A. Antonyak, Richard A. Cerione, Siiri E. Iismaa, Dianna Willis, Sunghee Cho, and Rajiv R. Ratan, which appeared on pages 6561-6569 of the May 9, 2012 issue, the authors regret that not all the funding sources were cited in the accepted version of the Acknowledgments. The corrected Acknowledgments are as follows: This work was supported by the National Institutes of Health (Grant P01 NIA AG014930, Project 1 to R.R.R.; Grants HL082511/HL82511-04S1 to S.C.), the Dr. Miriam and Sheldon G. Adelson Medical Research Foundation (R.R.R.), and the Burke Foundation (R.R.R. and S.C.). S.F.S. is a Goldsmith Fellow.

DOI: 10.1523/JNEUROSCI.2552-12.2012 